\title{
Determination of Viscosity Average Molar Masses of Polyethylene in a wide range using rheological measurements with a harmless solvent.
}

Mohammad Abou Taha ${ }^{a}$, Véronique Bounor-Legaréa, Fabiana Nascimento de Andrade ${ }^{b}$, Roberta Lopes do Rosariob ${ }^{\text {, Timothy F.L. McKenna }}{ }^{b}$, René Fulchiron ${ }^{a}$

a Univ Lyon, Université Claude Bernard Lyon 1, CNRS UMR 5223, Ingénierie des Matériaux Polymères, 15 Blvd Latarjet, F-69622, Villeurbanne, France

b Univ Lyon, Université Claude Bernard Lyon 1, CNRS UMR 5128, Catalyse, Polymérisation, Procédés et Matériaux, CPE-Lyon, 43 Blvd du 11 Novembre 1918, F-69616 Villeurbanne, France

*Corresponding Author: rene.fulchiron@univ-lyon1.fr

Abstract:

Rheological measurements of polyethylene solutions in a novel non-toxic solvent were used to determine the Mark-Houwink parameters for PE of widely different molecular weights to assess the viscosity average molar mass for PE of several millions of g. $\mathrm{mol}^{-1}$. Solutions of high density polyethylene that had been previously characterized by size exclusion chromatography were prepared in a harmless naphthenic oil. The intrinsic viscosities were obtained by varying the concentrations of the different calibration samples solutions using a rotational rheometer equipped with a Couette cell. The intrinsic viscosities were determined by both Huggins and Kraemer descriptions of the viscosity variations with concentration. Subsequently, a calibration curve of intrinsic viscosities versus the molar mass was plotted, and the parameters of the Mark-Houwink-Sakurada equation were obtained for polyethylene in naphthenic oil. Using this equation and the newly estimated parameters, the viscosity average molar mass of a high molar mass polyethylene and a commercial ultra high molar mass polyethylene were been determined by measuring their respective intrinsic viscosities. Finally, the method has been validated by comparing these results to values obtained by standard viscosimetry in 1,2,4trichlorobenzene and to the values given by the supplier, obtained by other methods. 


\section{Introduction:}

Polyethylene (PE) represents the most widely produced polymeric resin in the world, with an annual production rate of over 100 million tons. It is used in applications in major economic sectors such as packaging, construction, automotive, electronics, energy, agriculture, textile, and medical devices. It is known for having a profusion of properties, despite the fact that it is made from very simple molecules containing only hydrogen and carbon atoms. The tremendous range of properties that one can obtain from different PE is the result of the control of the chain architecture in terms of branching and molar mass distribution (MWD). Average molar masses of polyethylene range from a few tens of thousands to several millions, or tens of millions for ultra high molar mass species. Therefore, it is necessary to be able to characterize the branching and the molar mass distribution accurately. The former can be done using advanced technologies such as NMR [1, 2], but this kind of methods is not suitable for control since they are expensive, slow, and extensively laborious. Other technologies like high temperature size exclusion chromatography (HT-SEC) can be used to measure molar mass distributions of any shape. However the machines can be expensive, are quite delicate and the measurements can take several hours. Furthermore, it is extremely difficult to accurately measure the MWD of high molecular weight products with SEC $[3,4]$. Simple methods like measuring the melt flow rate or melt flow index are often used at production sites as these methods are quick, easy and robust. Unfortunately we are limited to molar masses on the order of 200000 to $300000{\mathrm{~g} . \mathrm{mol}^{-1}}^{-1}$ at most. However, since linear PE resins constitute $75 \%$ of the total polyethylene production, a quick, reliable and safe method of characterization of molar mass, and in particular of high to ultrahigh molar masses would be very useful.

In this paper, the interest is also focused on the estimation of a broad range of average molar masses including ultra high molar mass polyethylene (UHMWPE). UHMWPE is an extremely useful polymer for a number of applications, and is generally defined as a PE with a weight average molar mass of over $1000000 \mathrm{~g} \cdot \mathrm{mol}^{-1}$. It is notoriously difficult to characterize its molar mass. Therefore, an indirect measurement was used through the determination of the limiting viscosity number (LVN), also known as intrinsic viscosity $([\eta])$ instead of using conventional SEC whose results are disputed and often considered as distorted for high molar masses mainly because the columns are not adapted anymore. The measurement of [ $\eta$ ] gives access to the viscosity average molar mass $M_{V}$ (Eq. 1), known to be close to the mass average molar mass measured using conventional techniques.

$$
M_{v}=\left(\frac{\sum M_{i}^{1+\alpha} N_{i}}{\sum M_{i} N_{i}}\right)^{\frac{1}{\alpha}}
$$


where $\alpha$ is the Mark-Houwink exponent that will be used throughout this paper. It is related to the interaction between the polymer and the solvent and more precisely to the configuration of the chain in solution. Its values are typically between 0.5 and 0.8 . The value is 0.5 for a theta solvent, and it is closer to 0.8 for a good solvent, based on the definition of interactions between solvents and polymers by Flory and the calculation of the radius of gyration of a polymer in solution [5-7].

Several methods have been developed to determine the viscosity average molar mass of high molar mass polymers, e.g., by fractionation of high molar mass polymers [8], capillary viscosimetry [9] often using a Ubbelohde viscometer where outflow duration is proportional to the viscosity [10], and other similar techniques. For polyethylene, the norms that were developed along with the published articles, discuss the determination of the viscosity average molar mass using Mark-Houwink parameters that were determined beforehand using intrinsic viscosity measurements or other methods, i.e., SEC, light scattering and membrane osmometry, in high toxicity solvents [6]. The most commonly used solvents in the determination of the viscosity average molar mass are decalin [11], 1,2,4-trichlorobenzene (TCB) [1214], tetralin [15], o-dichlorobenzene [16] along with some of the reported theta solvents like biphenyl, dodecanol, decanol-1, diphenyl ether, and diphenylmethane [17]. These solvents are majorly classified as harmful and toxic $[18,19]$, and constitute serious health hazards as it has been reported for some being carcinogenic [20]. Fortunately, a much less toxic solvent, the dibutoxymethane, has been recently tested with success for Size Exclusion Chromatography of polyolefins [21-23]. Nevertheless, the reported measurements are limited to relatively low molecular weights.

Moreover, as shown in a very recent IUPAC Technical Report [24], despite great cautions in carrying out the measurements, the accuracy of measurements remains a major issue since a very large discrepancy can be obtained (a factor 3 for the intrinsic viscosity and a factor more than 2 for the Molecular weight).

In this paper, we propose to demonstrate the usefulness of a non-toxic alternative to these compounds and to evaluate the application of a naphthenic process oil to determine the viscosity average molar mass of polyethylenes of a very wide range of molar masses. This oil, Nytex $820^{\circledR}$, is composed of heavy naphthenic hydrotreated distillates, a complex combination of hydrocarbons obtained by treating a petroleum fraction with hydrogen in the presence of a catalyst. It is often used as processing oil to manufacture ultra high molar polyethylene (UHMWPE) for lead-acid batteries separators $[25,26]$ for example.

The measurements of $[\eta]$ for different polyethylene samples in process oil using a rotational rheometer and based on the intrinsic viscosity determination from both Huggins [27] and Kraemer [28] plots have 
been performed. In this respect, it can be mentioned that the use of a rotational rheometer (equipped with a Couette cell) is not a current way of measuring the intrinsic viscosity. Nevertheless, when this device is available in a laboratory, it will be shown later on that this can be one of its uses among others (Obviously not the only one given the price of such an apparatus compared to this of the Ubbelohde device). From the results, a calibration curve of HDPEs $[\eta]$ versus their molar mass predetermined by SEC in TCB was plotted as described by the Mark-Houwink-Sakurada equation. Thus, the new Mark-HouwinkSakurada parameters for polyethylene in process oil at the chosen temperature have been deduced, making it possible to determine the viscosity average molar mass of high molar mass polyethylene from their intrinsic viscosity measurements using a rotational rheometer.

\section{Materials}

Polyethylene homopolymers samples were used for the calibration presented in this work. Five HDPE samples were produced in a spherical semi-batch reactor [29-31] for this study. Four of them (from HDPE2 to HDPE5) will be used for setting up the calibration because their molar masses were in the range measurable by HT-SEC. The fifth sample (HMWPE8) was of higher average molar mass and could not be accurately characterized by SEC. In addition, an UHMWPE sample, GUR4150 ${ }^{\circledR}$, was produced and supplied by Celanese Ticona. It has a reported viscosimetric molar mass of approximately 9200000 g.mol${ }^{-1}$ calculated by the supplier using Margolies equations.

Nytex $820^{\circledR}$ oil is a naphthenic oil produced by Nynas and composed of heavy naphthenic hydrotreated distillates. It has an initial boiling point higher than $250^{\circ} \mathrm{C}$ and has thermal stability up to $280^{\circ} \mathrm{C}$. Moreover, it has a viscosity of about $2.2 \times 10^{-3}$ Pa.s at $165^{\circ} \mathrm{C}$ and has a density of about $0.91 \mathrm{~g} . \mathrm{cm}^{-3}$.

\section{Methods}

\section{Size Exclusion Chromatography (SEC)}

High temperature SEC analyses were performed using a Viscotek system (from Malvern Instruments) equipped with three columns (PLgel Olexis $300 \mathrm{~mm} \times 7 \mathrm{~mm}$ I.D. from Agilent Technologies). $200 \mu \mathrm{L}$ of sample solutions with a concentration of $3 \mathrm{mg} \mathrm{mL}^{-1}$ were eluted in 1,2,4-trichlorobenzene (TCB) using a flow rate of $1 \mathrm{~mL} \mathrm{~min}{ }^{-1}$ at $150{ }^{\circ} \mathrm{C}$. The mobile phase was stabilized with 2,6-di-tert-butyl-4-methylphenol (butylated hydroxytoluene, BHT, $400 \mathrm{mg} \mathrm{L}^{-1}$ ). Online detection was performed with a differential refractive index detector and a dual light scattering detector (LALS and RALS) for absolute molar mass measurement. The OmniSEC 5.02 software was used for calculations. 
The relationship between Intrinsic Viscosity $([\eta])$ and Viscosity-average Molar Mass $\left(M_{v}\right)$

Before beginning to look at the experimental results, it might be useful to recall some definitions related to the intrinsic viscosity measurements.

$\eta_{\text {rel }}$ is defined as the relative viscosity or the ratio of the viscosity $\eta_{0}$ of the dilute polymer solution, at a specific concentration, over the viscosity of the pure solvent at the same temperature:

$$
\eta_{\text {rel }}=\frac{\eta_{0}}{\eta_{\text {solv }}}
$$

$\eta_{\text {spec }}$ is the specific viscosity defined as the ratio of the difference between solution and solvent viscosities and the solvent viscosity:

$$
\eta_{\text {spec }}=\frac{\eta_{0}-\eta_{\text {solv }}}{\eta_{\text {solv }}}=\eta_{\text {rel }}-1
$$

$\eta_{\text {reduced }}$ is defined as the reduced viscosity or the viscosity number according to the IUPAC:

$$
\eta_{\text {reduced }}=\frac{\eta_{0}-\eta_{\text {solv }}}{C \eta_{\text {solv }}}=\frac{\eta_{\text {spec }}}{C}
$$

Where $C$ is the concentration in $\mathrm{g} \cdot \mathrm{dL}^{-1}$ of the polymer solution. And finally, $\eta_{\text {inh }}$, which is the inherent viscosity or the logarithmic viscosity number (IUPAC), is defined as follows:

$$
\eta_{i n h}=\frac{\ln \eta_{r e l}}{C}
$$

Flory introduced the reduced viscosity as the ability of a polymer to increase the relative viscosity of the solution [7]. The intrinsic viscosity is introduced by Eq. 6 from the description of Huggins of the reduced viscosity [27] $\frac{\eta_{\text {spec }} \text { : }}{C}$

$$
\frac{\eta_{\text {spec }}}{C}=[\eta]+k_{H}[\eta]^{2} C
$$

where $[\eta]$ is the intrinsic viscosity and $k_{H}$ (dimensionless) is known as the Huggins constant. For a concentration which tends to zero, the inherent properties of a polymer solution can be captured by obtaining the intrinsic viscosity as follows:

$$
[\eta]=\lim _{c \rightarrow 0} \frac{\eta_{\text {spec }}}{C}=\lim _{c \rightarrow 0} \frac{\eta_{0}-\eta_{\text {solv }}}{C \eta_{\text {solv }}}
$$


On the other hand, Kraemer described the intrinsic viscosity using the inherent viscosity calculated from the relative viscosity of the solution [28]:

$$
\frac{\ln \eta_{r e l}}{C}=[\eta]-k_{K}[\eta]^{2} C
$$

According to this description, the intrinsic viscosity can be defined as the limiting value of the inherent viscosity as [28]:

$$
[\eta]=\lim _{c \rightarrow 0} \frac{\ln \eta_{\text {rel }}}{C}
$$

The relationship between the intrinsic viscosity and the molar mass derives from Einstein's description of the viscosity in a dilute regime. It emphasizes the fact that the intrinsic viscosity is direct information on the interactions between a polymer chain and the solvent molecules and insists on the necessity of measurements in the dilute regime. The intrinsic viscosity is related to the hydrodynamic volume of the polymer which is considered as a spherical particle moving in a solvent, the radius of this particle being assimilated to the radius of gyration of the polymer chain, $R_{g}$. Knowing that $R_{g}$ is proportional to the square root of the molar mass of a polymer having a random coil configuration, a relationship between the intrinsic viscosity and the molar mass can be given by the Mark-Houwink-Sakurada equation [7, 32, 33]:

$$
[\eta]=K M_{v}^{\alpha}
$$

where $\alpha$ and $K$ are the Mark Houwink parameters. They are specific for a polymer at a defined temperature and in a specific solvent [33]. Based on the used calibrating polymers, these coefficients would make it possible to determine the viscosity average molar mass $\left(M_{V}\right)$ of a large range of polymers with even high or ultra high molar masses after the measurement of their intrinsic viscosity.

It is important to note that the concentrations must be controlled in order to ensure the preparation of solutions in the dilute regime. This is confirmed by obtaining linear plots of both Kraemer's inherent viscosity and Huggins' reduced viscosity on the whole range of the explored concentrations. Then, the sum of Huggins and Kraemer constants would be equal to 0.5 as a mathematical consequence [34].

\section{Capillary Viscosimetry}

The measurements of $M_{V}$ for polyethylenes with molar masses higher than 1000000 g.mol ${ }^{-1}$ were carried using Intrinsic Viscosity Analyser from Polymer Char. First, 4-5 mg of polyethylene was weighed. 
After that, the vials with polymer were placed into the external tray autosampler of the autosampler at room temperature. Then, the instrument takes the vials into the dissolution oven and fills them with 16 $\mathrm{mL}$ of trichlorobenzene (TCB) before starting the stirring under nitrogen at $150^{\circ} \mathrm{C}$ for 3 hours. The $M_{v}$ was calculated from intrinsic viscosity data, provided by the device's manufacturer using Mark-Houwink parameters $\alpha=0.705$ and $K=5.188 \times 10^{-4} \mathrm{dL}^{-g^{-1}}$.

Rotational rheometry

Rheological measurements of solutions were carried out using an ARES-G2 (TA Instruments) rotational rheometer equipped with a Couette cell at $T=165^{\circ} \mathrm{C}$, a temperature higher than the melting temperature of polyethylene to ensure the most efficient condition of solubility of the polymer resins in the process oil. This experiment was conducted under nitrogen flow to limit the oxidation of process oil at high temperature. Polymer samples $(<4 \mathrm{mg})$, as well as the process oil $(5-7 \mathrm{~g})$, were weighed directly inside the Couette geometry using a precision balance $\left(10^{-4} \mathrm{~g}\right)$ to limit the weighing error, especially for nascent powder samples. Then, the preparation of the solution was done directly in the Couette's cell in order to avoid a modification of the concentration (very low in our case) and/or a phase separation due to eventual decrease of the temperature during the solution transfer in the cell. Then, a time sweep experiment was performed at $50 \mathrm{~s}^{-1}$ to ensure the dissolution for typically 1500 to $2000 \mathrm{sec}$. This dissolution time turned out to be fully sufficient (see Figure S1 in Supplemental Material). Afterward, a flow sweep experiment is performed, and the values of Newtonian viscosities were extracted from the Newtonian plateau for each of the prepared solutions, generally in the range of shear rates between $10 \mathrm{~s}^{-1}$ and $100 \mathrm{~s}^{-1}$.

Results and discussion

In this work, important precautions must be taken, especially when determining the Mark-Houwink parameters in order to ensure sufficient reliability of the obtained values. This applies in particular to the accuracy of the concentration values and the homogeneity of the solutions which is essential to guarantee the consistency of the measured viscosities. In fact, for measuring the intrinsic viscosity, the solution must be in the dilute regime, that is, with no interactions between polymer molecules. However, the concentrations corresponding to the dilute regime depend on the molar mass of the polymer and the higher is the molar mass, the lower must be the concentration. This is why in the 
obtained results, the same concentrations have not been explored for all of the range of the investigated molar masses. Moreover, the solution must be prepared at high temperature to ensure the complete polymer dissolution.

As seen in Figure 1, for the same concentration, the Newtonian viscosity of a polymer solution increases with the molar mass of the polyethylene. However, the viscosity increases also with the polyethylene concentration as illustrated in Figure 2 with the HDPE4 sample.

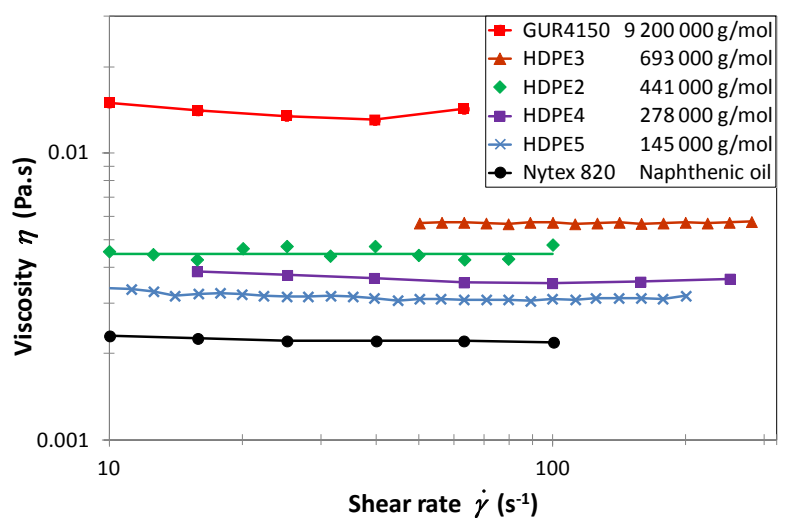

Figure 1: Viscosity as a function of shear rate for solutions of different molar mass $\left(\mathrm{g}^{\mathrm{m}} \mathrm{mol}^{-1}\right)$ of PE in oil at the same concentration $\left(C=0.2 \mathrm{~g} . \mathrm{dL}^{-1}\right)$ at $165^{\circ} \mathrm{C}$ under nitrogen flow.

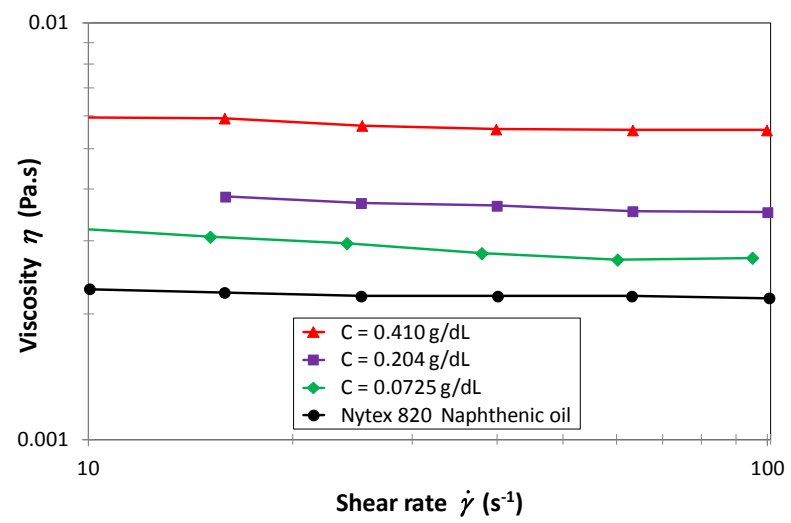

Figure 2: Viscosity as a function of shear rate for HDPE4 (278 $\left.000 \mathrm{~g} . \mathrm{mol}^{-1}\right)$ solutions in oil at different polymer concentrations at $165^{\circ} \mathrm{C}$ under nitrogen flow.

To increase the reliability of the measurements, both Kraemer's and Huggins's expressions were used. In Figure 3, both inherent viscosity (Kraemer) and reduced viscosity (Huggins) plots appear linear. The error bars indicate the uncertainty deduced from the variation of the absolute measured viscosities. Moreover, the sum of the obtained Huggins and Kraemer constants was relatively close to 0.5 for all samples. Hence, it is verified a posteriori that the experiments were indeed carried out in the dilute regime. Theoretically, both lines should give the same intercept at $c=0$. However, practically, they can be slightly different, likely because of the concentration measurements uncertainty which can be relatively 
important. Nevertheless, in these cases, the intrinsic viscosity was considered as the average value of these intercepts. By this way, the possible uncertainty on the concentration which would affect the abscissa axis of the plots is not entirely transferred to the intrinsic viscosity values. The obtained intrinsic viscosities for all of the calibrating samples are presented in Table 1 . The viscosity measurements of the rest of the calibrating samples are reported in Supplemental Material.
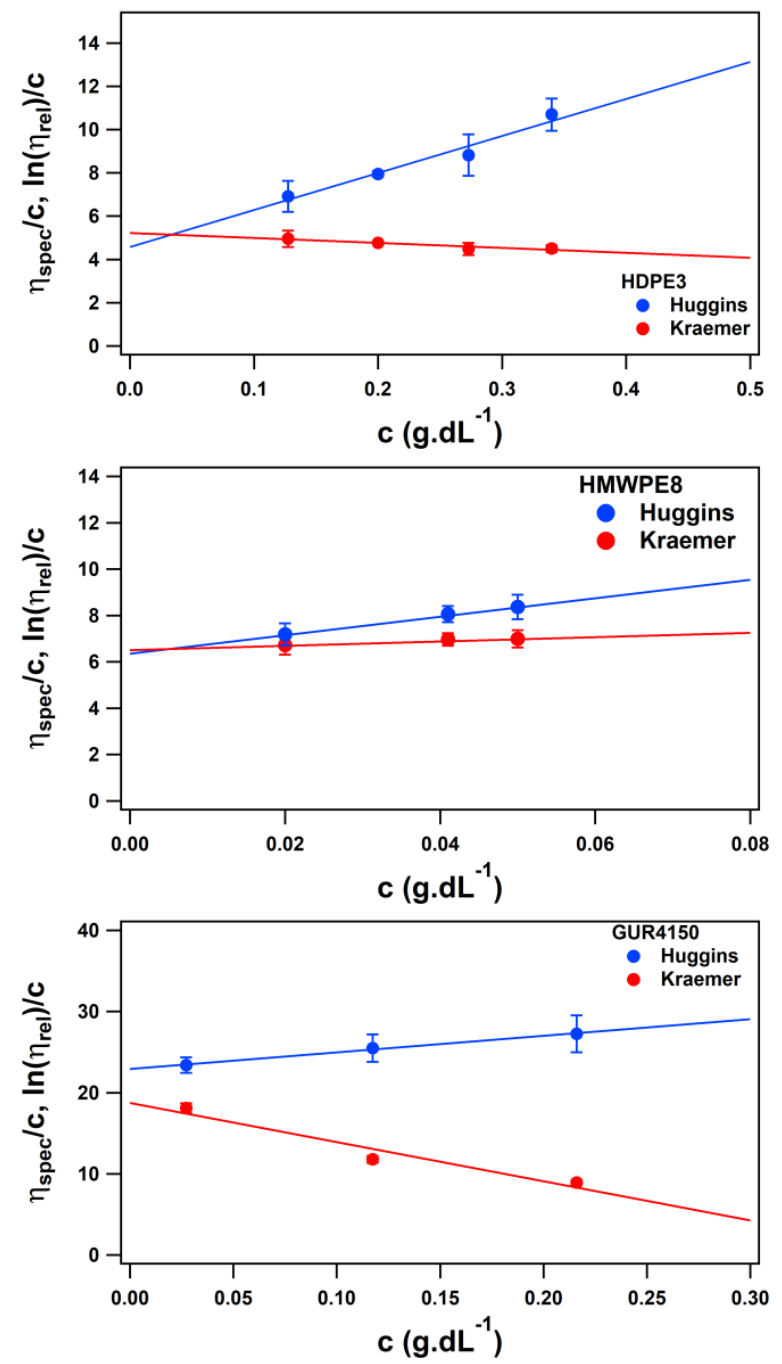

Figure 3: Kraemer's inherent viscosity and Huggins' reduced viscosity as a function of the concentration for HDPE3, HMWPE8, and UHMWPE GUR4150 solutions in oil. The curves for the determination of [ $\eta$ ] of the other calibrating samples are reported in Supplemental Material.

Table 1: Experimental results of Intrinsic Viscosity of the calibrating HDPE samples $(2,3,4,5)$.

\begin{tabular}{cccc}
\hline Sample designation & Intrinsic Viscosity $\left(\mathbf{d L} \cdot \mathrm{g}^{-1}\right)$ & $\mathbf{M}_{\mathbf{w}}\left(\mathbf{g} \cdot \mathbf{m o l}^{-1}\right)^{*}$ & $\mathbf{M}_{\mathbf{n}}\left(\mathbf{g} \cdot \mathbf{m o l}^{-1}\right)^{*}$ \\
\hline HDPE5 & 1.98 & 145500 & 33000 \\
HDPE4 & 3.07 & 278000 & 59000 \\
HDPE2 & 3.42 & 441000 & 101000 \\
HDPE3 & 4.91 & 693000 & 172000 \\
\hline
\end{tabular}

* Determined by SEC analysis 
As expected, the intrinsic viscosity clearly increases with the polyethylene molar mass (Table 1). These results are used to plot the calibration curve in the log-log scale as described by the Mark-Houwink Sakurada (Eq 10).

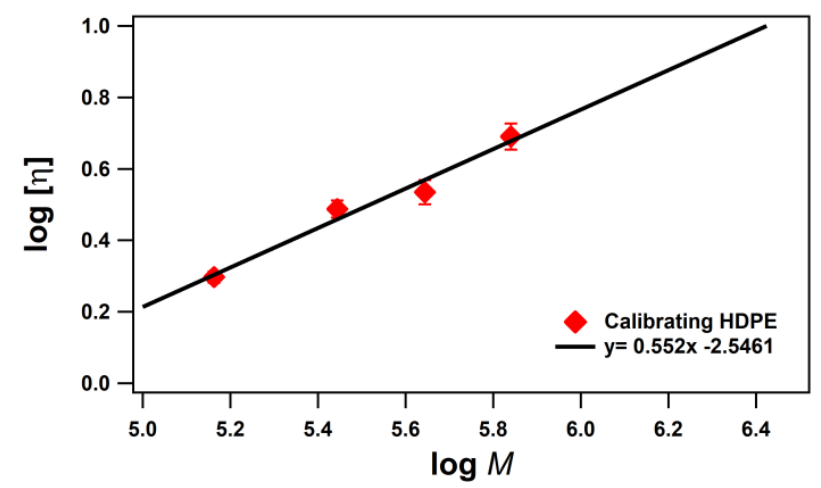

Figure 4: Calibration curve following the Mark-Houwink Sakurada Equation using the calibrating HDPE samples (determined by SEC). In black, the obtained calibration line.

The slope of the straight line in Figure 4 gives $\alpha=0.552$ and the $y$-intercept gives $\log K=-2.5461$. Thus, the Mark-Houwink Sakurada Equation for polyethylene in process oil at $165^{\circ} \mathrm{C}$ is written as:

$$
[\eta]=2.84 \times 10^{-3} M^{0.552} \text { at } 165^{\circ} \mathrm{C}
$$

The obtained alpha value is consistent as it respects its upper and lower limits, as previously discussed $(0.5<\alpha<0.8)$. Based on this result, the molar mass of higher molar mass samples can be obtained from the solution rheological measurements. Indeed, the intrinsic viscosities of GUR4150 and of HMWPE8 were measured following the same procedure and values of $20.83 \mathrm{~g} . \mathrm{dL}^{-1}$ and of $6.43 \mathrm{~g} \cdot \mathrm{dL}^{-1}$ were respectively obtained (Figure 3). Then, by reversing Eq. 11, the viscosity average molar mass is determined: $M_{V}=10040000$ g.mol ${ }^{-1}$ for GUR4150, which is very close to the value mentioned by the supplier (9 $200000 \mathrm{~g} \cdot \mathrm{mol}^{-1}$ ) and $M_{V}=1192000 \mathrm{~g} \cdot \mathrm{mol}^{-1}$ for HMWPE8. These results will be verified by similar viscosimetry method in TCB.

As size exclusion chromatography may be questionable for high molar mass polymers $\left(>10^{6} \mathrm{~g} / \mathrm{mol}\right.$ ) and in order to control further the values of molar mass of polyethylenes used in the study (the investigated HMWPE8 and GUR4150), intrinsic viscosity measurements in TCB were performed using the viscometer. The obtained viscosity average molar masses of GUR4150 and HMWPE8 samples are consistent with the $M_{V}$ measurements using the rotational rheometer and the obtained Mark Houwink Sakurada parameters as seen in Table 2. For GUR4150, the obtained values are $10040000 \mathrm{~g} \cdot \mathrm{mol}^{-1}$ and $9418000 \mathrm{~g} \cdot \mathrm{mol}^{-1}$ respectively from the rheological measurements in naphtenic oil and from the Viscometer in TCB. These values remain close to that given by the supplier. The same accordance is found for HMWPE8 sample, 
although the value of $M_{V}$ obtained from the viscometer (1 $677000 \mathrm{~g} \cdot \mathrm{mol}^{-1}$ ) is relatively higher than the results obtained using rheology in oil $M_{V}\left(1192000 \mathrm{~g} \cdot \mathrm{mol}^{-1}\right)$. Nevertheless, it can be mentioned that from another rheological measuring method, a value of $M_{W}\left(1400000\right.$ g.mol $\left.{ }^{-1}\right)$ much closer to 1192000 g.mol ${ }^{-1}$ was obtained for the same material [35].

Table 2: Average molar mass from Viscometer and SEC analysis and supplier values for HMWPE8 and GUR4150 respectively.

\begin{tabular}{|c|c|c|c|}
\hline Sample designation & $\boldsymbol{M}_{V}$ (Rheology) in oil & $\boldsymbol{M}_{V}$ (Viscometer) in TCB & $\boldsymbol{M}_{V}$ Supplier Information \\
\hline HMWPE8 & $1192000 \mathrm{~g} \cdot \mathrm{mol}^{-1}$ & $1677000 \mathrm{~g} \cdot \mathrm{mol}^{-1}$ & - \\
\hline GUR4150 & $10043000 \mathrm{~g} \cdot \mathrm{mol}^{-1}$ & $9418000 \mathrm{~g} \cdot \mathrm{mol}^{-1}$ & $9200000 \mathrm{~g} \cdot \mathrm{mol}^{-1}$ \\
\hline
\end{tabular}

To complete, in Figure 5, the calibration straight line extrapolated to high values, together with the values for HMWPE8 and GUR4150 obtained from the viscometer measurements are plotted. As already mentioned, the value for HMWPE8 is slightly apart from the line but all together, the results are very consistent despite the fact that the extrapolation was made on a large scale. It can be added that, from the standard deviations obtained for the measured viscosities, the uncertainty of the extrapolations to the intrinsic viscosities was deduced. Then, this uncertainty was transmitted in Figure 4 and Figure 5. However, due to the broadness of data range and the logarithmic plots, these error bars remain very small comforting the results reliability (In Figure 5, error bars are indistinguishable from the symbols).

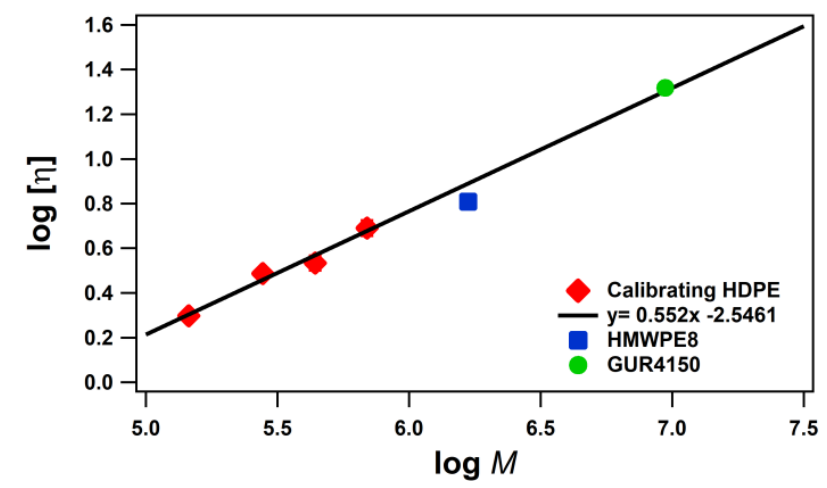

Figure 5: Calibration straight line of polyethylene in naphthenic oil at $165^{\circ} \mathrm{C}$ and comparison with measured values for all samples (ranging from $145000 \mathrm{~g} \cdot \mathrm{mol}^{-1}$ to $10000000 \mathrm{~g} \cdot \mathrm{mol}^{-1}$ ).

\section{Conclusion}

In this study, a method for measuring the viscosity average molar mass of polyethylene in a novel nontoxic solvent has been elaborated. A rotational rheometer equipped with a Couette's cell was used to determine the intrinsic viscosities of four synthesized high density polyethylene samples of known molar 
mass. The used solvent was naphthenic oil which can be an advantageous alternative for the more and more questioning toxic solvents used for their analysis. The intrinsic viscosities of the calibrating samples were used to obtain a calibration curve from which the Mark Houwink Sakurada parameters for polyethylene in naphthenic oil at the working temperature $\left(T=165^{\circ} \mathrm{C}\right)$ has been extracted. The obtained parameters $\left(\alpha=0.552, K=2.84 \times 10^{-3} \mathrm{dL}^{-g^{-1}}\right)$ were then used to determine the viscosity average molar mass of a high molar mass polyethylene and an ultra-high molecular weight polyethylene. The results were contiguous with the values communicated by the supplier and those experimentally acquired using viscosimetry, hence validating the proposed procedure. The findings of this paper cover a wide range of molar mass of polyethylene (145 $\left.000-10000000 \mathrm{~g} \cdot \mathrm{mol}^{-1}\right)$ and are of relevance in determining very high molar mass that cannot be obtained conclusively with the existing chromatography techniques. It must be conceded however that the procedure cannot be easily automated as it is for SEC or Ubbelohde device.

Supplemental Material:

See Supplemental Material for the viscosity measurements of all the calibrating samples.

\section{Acknowledgements:}

The authors gratefully acknowledge Solvay group and ANRT for funding the PhD thesis of Mohammad Abou Taha (CIFRE N 2016/1462). 
References:

1 Fleischer, G. 1985. The effect of polydispersity on measuring polymer self-diffusion with the NMR pulsed field gradient technique. Polymer 26:1677-1682.

2 Fleischer, G. 1985. A critical reconsideration of polymer self-diffusion data measured by the NMR pulsed field gradient technique. Makromol. Chem., Rapid Commun. 6:463-467.

3 Prabhu, K., Brüll, R., Macko, T., Remerie, K., Tacx, J., Garg, P., Ginzburg, A. 2015. Separation of bimodal high density polyethylene using multidimensional high temperature liquid chromatography. J. Chromatogr. A. 1419: 67-80.

4 Hintersteiner, I., Himmelsbach, M., Buchberger W. W. 2015. Characterization and quantitation of polyolefin microplastics in personal-care products using high-temperature gel-permeation chromatography. Anal. Bioanal. Chem. 407:1253-1259.

5 Neira-Velázquez, M. G., Rodriguez-Hernandez, M. T., Hernández-Hernández, E., Ruiz-Martínez, A. R. 2013, in Handbook of Polymer Synthesis, Characterization, and Processing, ed: E. Saldívar-Guerra, E. Vivaldo-Lima, Hoboken, NJ: Ch. 17. John Wiley \& Sons, Inc.

6 Wagner, H. L. 1985. The Mark-Houwink-Sakurada equation for the viscosity of linear polyethylene. J. Phys. Chem. Ref. Data. 14:611-617.

$7 \quad$ Flory, P.J. 1953. Principles of polymer chemistry. Ithaca, NY: Cornell University Press.

8 Francis, P., Cooke Jr, R., Elliott, J. 1958. Fractionation of polyethylene. J. Polym. Sci. 31: 453-466.

9 Cannon, M., Fenske, M. 1938. Ind. Eng. Chem., Anal. Ed. 10: 297-301.

10 Ubbelohde, L. 1937. The principle of the suspended level: applications to the measurement of viscosity and other properties of liquids. Ind. Eng. Chem., Anal. Ed. 9:85-90.

11 ASTM D4020-18 (2018). Standard Specification for Ultra-High-Molecular-Weight Polyethylene Molding and Extrusion Materials.

12 ASTM D6474-20 (2020). Standard Test Method for Determining Molecular Weight Distribution and Molecular Weight Averages of Polyolefins by High Temperature Gel Permeation Chromatography.

13 Crouzet, P., Martens, A., Mangin, P. 1971. Universal calibration in permeation chromatography. Application to polyethylenes, polypropylene, and ethylene-propylene copolymers. J. Chromatogr. Sci. 9:525-530.

14 Barlow, A., Wild, L. Ranganath, R. 1977. Gel permeation chromatography of polyethylene. I. Calibration. J. Appl. Polym. Sci. 21:3319-3329.

15 Duch, E., Küchler, L. 1956. Molgewichtsbestimmungen bei höheren Temperaturen $Z$. Elektrochem., Ber. Bunsenges. Phys. Chem. 60:218-229.

16 Pollock, D.J., Kratz., R. 1968. Practical Techniques For The Treatment Of Gel Permeation Chromatography Data. Sixth International Seminar on GPC, Miami Beach, October 1968.

17 Chiang, R. 1966. Temperature coefficient of the unperturbed dimension of linear polyethylene from intrinsic viscosity measurements in $\theta$ solvents. J. Phys. Chem. 70:2348-2352.

18 Brown, V., Muir, C., Thorpe, E. 1969. The acute toxicity and skin irritant properties of 1, 2, 4trichlorobenzene. Ann. Occup. Hyg. 12:209-212.

19 Kociba, R., Leong, B., Hefner, R., 1981. Subchronic toxicity study of 1, 2, 4-trichlorobenzene in the rat, rabbit and beagle dog. Drug Chem. Toxicol. 4:229-249.

20 NTP toxicology and carcinogenesis studies of decalin (CAS No. 91-17-8) in F344/N rats and B6C3F (1) mice and a toxicology study of decalin in male NBR rats (inhalation studies). National Toxicology Program technical report series. 2005, 513. 
Boborodea, A., Collignon, F., Brookes, A., 2015. Characterization of Polyethylene in Dibutoxymethane by High-Temperature Gel Permeation Chromatography with TripleDetection. Int. J. Polym. Anal. 20:316-322.

Boborodea, A., Mirabella, F.M., O'Donohue, S., 2016. Characterization of Low-Density Polyethylene in Dibutoxymethane by High-Temperature Gel Permeation Chromatography with Triple Detection. Chromatographia. 79:971-976.

Boborodea, A., Brookes, A., 2017. Polyolefin characterization in dibutoxymethane by high temperature gel permeation chromatography with a new evaporative light scattering detector. Polym. Test. 64:217-220

24 Bucknall, C., Altstädt, V., Auhl, D., Buckley, P., Dijkstra, D., Galeski, A., Gögelein, C., Handge U.A., He J., Liu C.Y., Michler, G., Piorkowska, E., Slouf, M., Vittorias, I., Wu, J.J., 2020. Structure, processing and performance of ultra-high molecular weight polyethylene (IUPAC Technical Report). Part 1: characterizing molecular weight. Pure Appl. Chem. 92:1469-1483. Toquet, F., Guy, L., Schlegel, B., Cassagnau, P., Fulchiron, R. 2016. Effect of the naphthenic oil and precipitated silica on the crystallization of ultrahigh-molecular-weight polyethylene. Polymer 97:63-68.

Toquet, F., Guy, L., Schlegel, B., Cassagnau, P., Fulchiron, R. 2019. Combined roles of precipitated silica and porosity on electrical properties of battery separators. Mater. Chem. Phys. 223:479485.

27 Huggins, M.L. 1942. The viscosity of dilute solutions of long-chain molecules. IV. Dependence on concentration. J. Am. Chem. Soc. 64:2716-2718.

Kraemer, E.O. 1938. Molecular weights of celluloses and cellulose derivates. Ind. Eng Chem. 30:1200-1203.

Namkajorn, M., Alizadeh, A., Somsook, E., McKenna, T.F. 2014. Condensed-Mode Cooling for Ethylene Polymerization: The Influence of Inert Condensing Agent on the Polymerization Rate. Macromol. Chem. Phys. 215:873-878.

Namkajorn, M., Alizadeh, A., Somsook, E., McKenna, T.F. 2015. Condensed mode cooling for ethylene polymerization: part I. The effect of different induced condensing agents on polymerization rate. Macromol. Chem. Phys. 216:903-913.

31 Namkajorn, M., Alizadeh, A., Somsook, E., McKenna, T.F. 2015. Condensed mode cooling for ethylene polymerization: part II. The effect of different condensable comonomers and hydrogen on polymerization rate. Macromol. Chem. Phys. 216:985-995. Mays, J. W., Hadjichristidis, N. 1991. in Modern methods of polymer characterization. ed. H.G. Barth, J.W. Mays, New York, NY: John Wiley \& Sons, Ch 7.

33 Brandrup, J. Immergut E. H., Grulke, E. A., Abe, A., Bloch, D.R. 1999. in Polymer Handbook, $4^{\text {th }}$ Ed., New York, NY: John Wiley \& Sons.

34 Pamies, R., Cifre, J.G.H., Martínez, M.d.C.L., de la Torre, J.G. 2008. Determination of intrinsic viscosities of macromolecules and nanoparticles. Comparison of single-point and dilution procedures. Colloid Polym. Sci. 286:1223-1231.

Namkajorn, M., Alizadeh, A., Romano, D., Rastogi, S., McKenna, T.F.L. 2016. Condensed Mode Cooling for Ethylene Polymerization: Part III. The Impact of Induced Condensing Agents on Particle Morphology and Polymer Properties. Macromol. Chem. Phys. 217:1521-1528. 
Supplemental Material:

Examples of time sweep experiments showing the stability of the measured viscosity for at least 30 minutes:

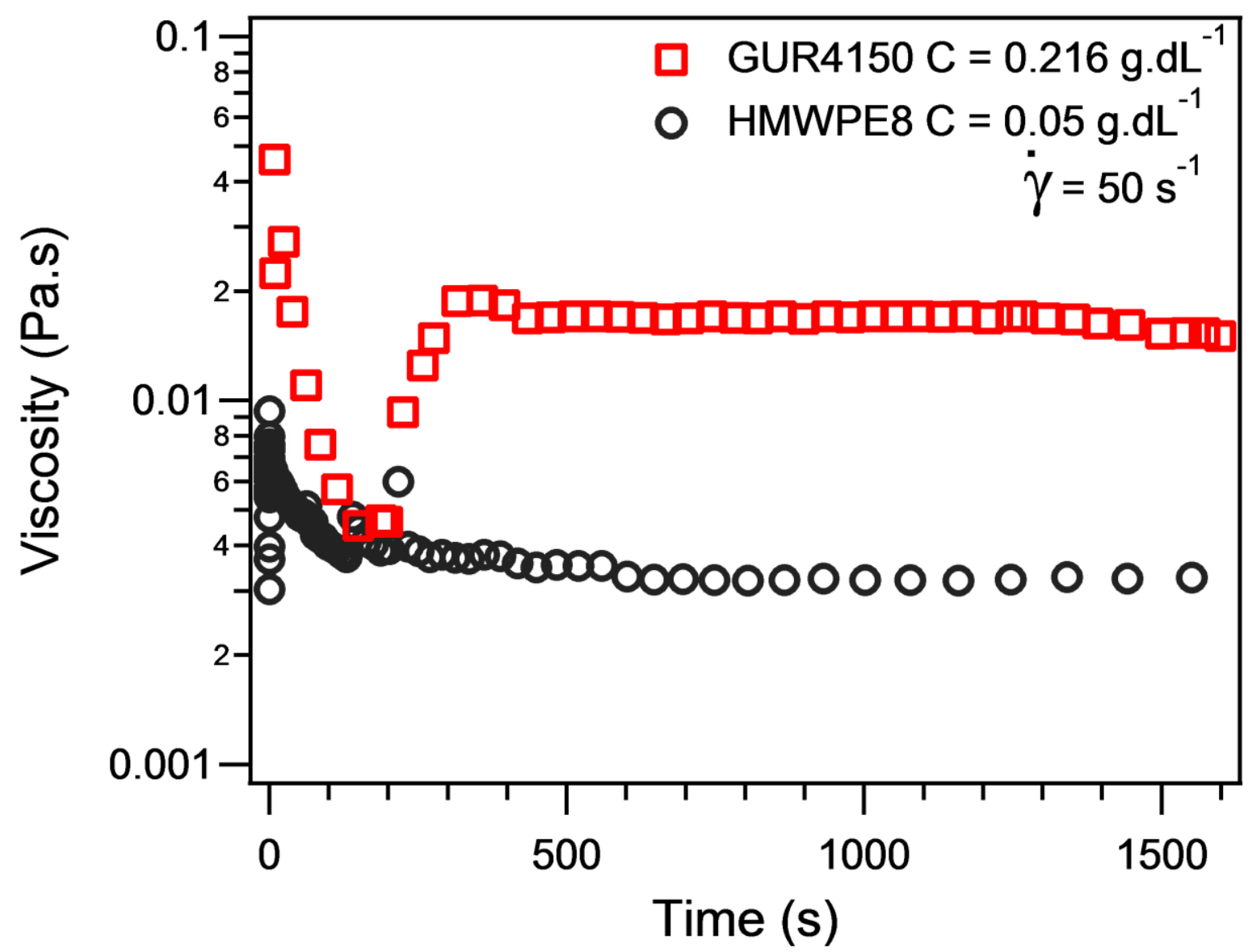

Figure S1: Measured Viscosity as a function of time one UHMWPE GUR4150 solution and one HMWPE8 solution in Nytex 820 oil $\left(\dot{\gamma}=50 \mathrm{~s}^{-1}, T=165^{\circ} \mathrm{C}\right)$. 


\section{Measured viscosity curves as a function of the shear rate for all of the PE solutions :}

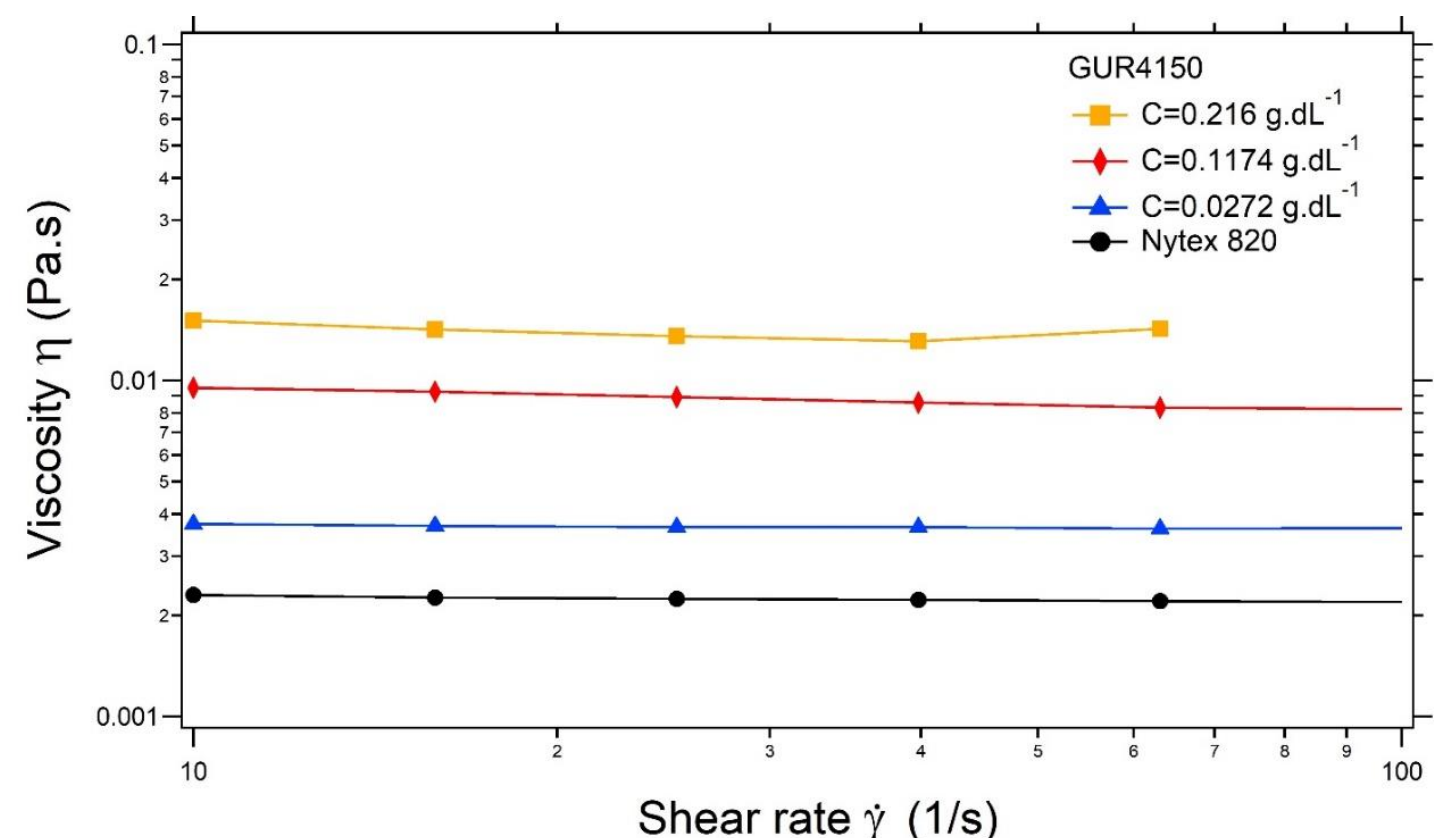

Figure S2 : Viscosity as a function of shear rate of UHMWPE GUR4150 solutions in Nytex 820 oil at different concentrations $\left(T=165^{\circ} \mathrm{C}\right)$.

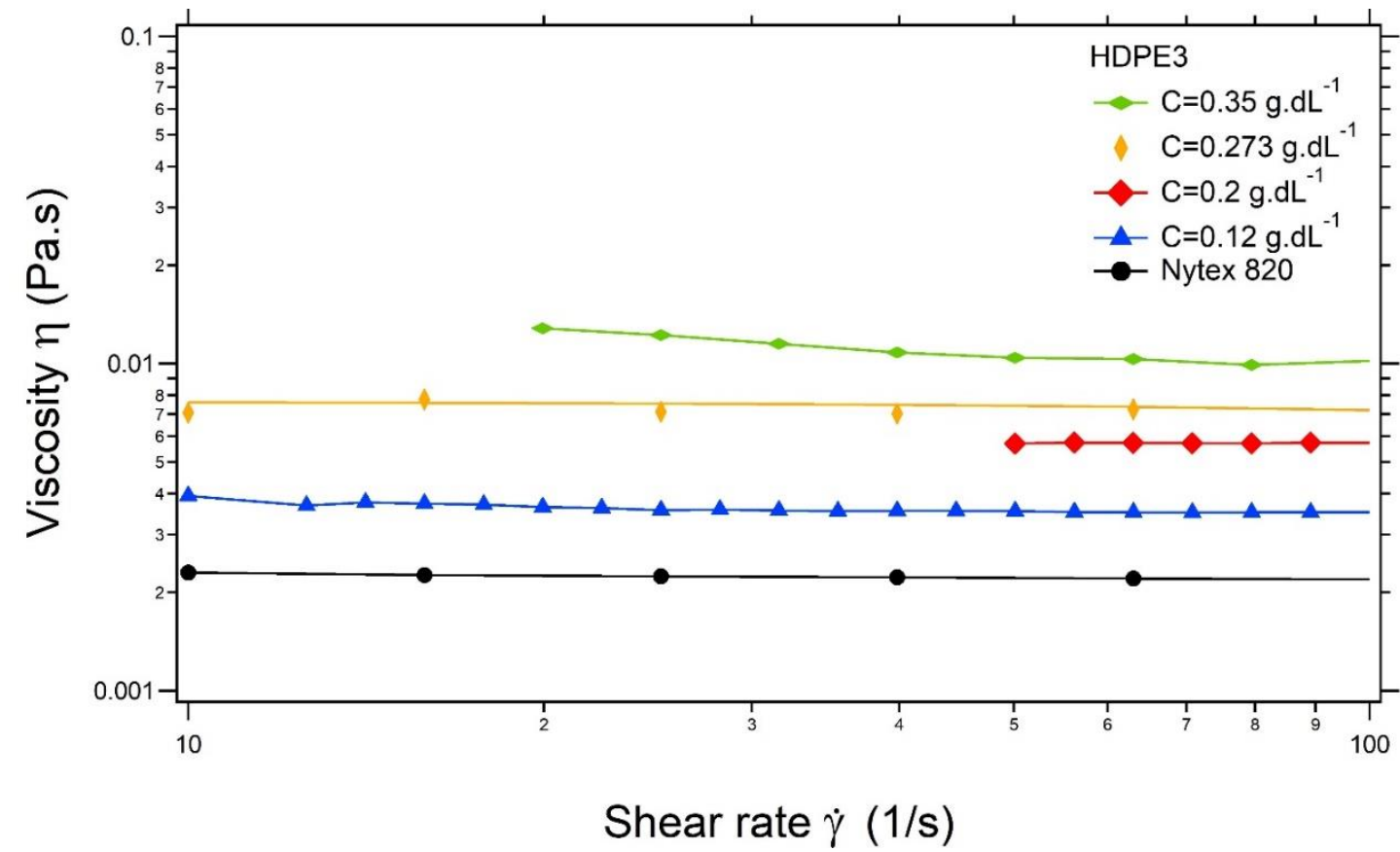

Figure S3 : Viscosity as a function of shear rate of HDPE3 $\left(693 \mathrm{~kg} \cdot \mathrm{mol}^{-1}\right)$ solutions in Nytex 820 oil at different concentrations $\left(T=165^{\circ} \mathrm{C}\right)$. 


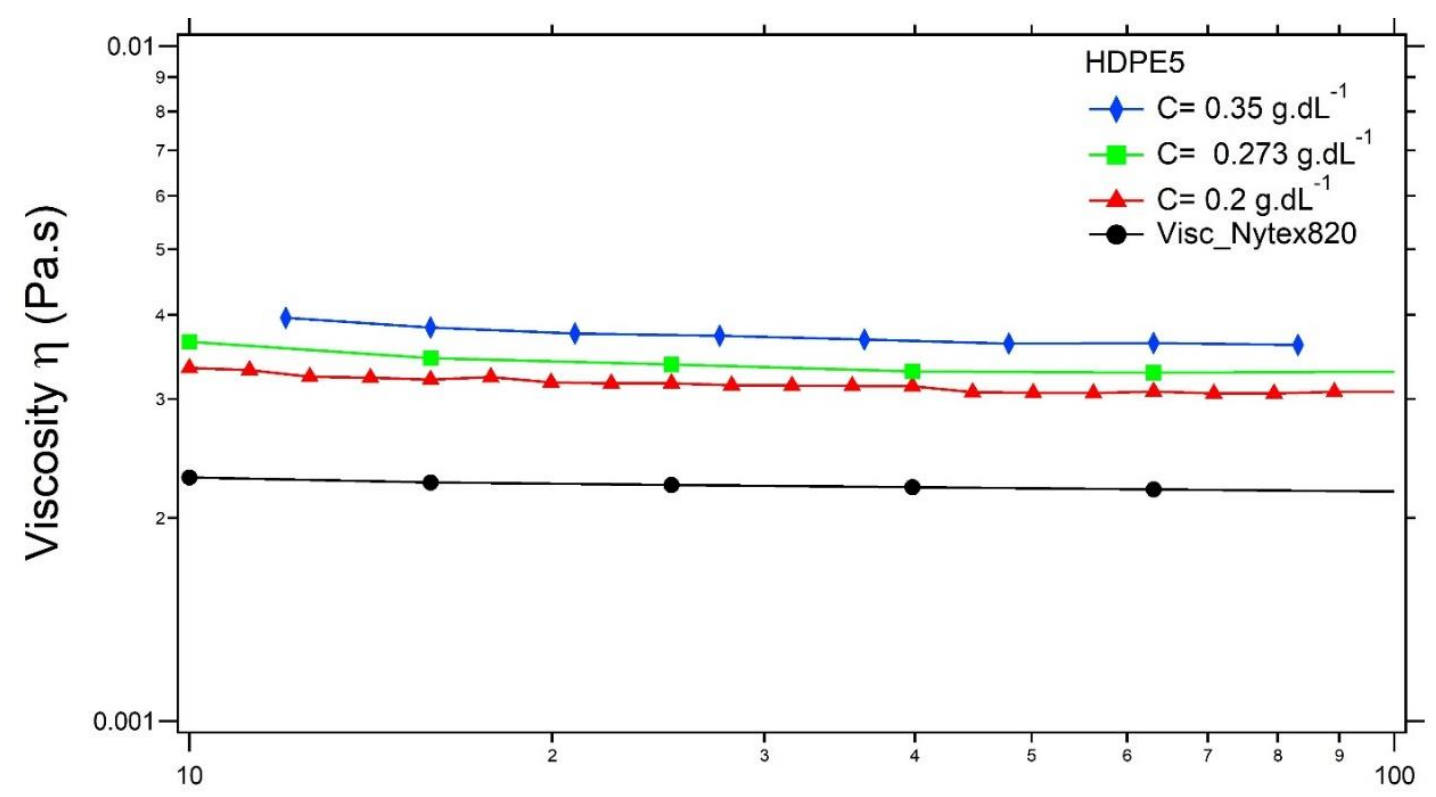

Shear rate $\dot{\gamma}(1 / s)$

Figure S4 : Viscosity as a function of shear rate of HDPE5 (145 kg.mol-1) solutions in Nytex 820 oil at different concentrations $\left(T=165^{\circ} \mathrm{C}\right)$.

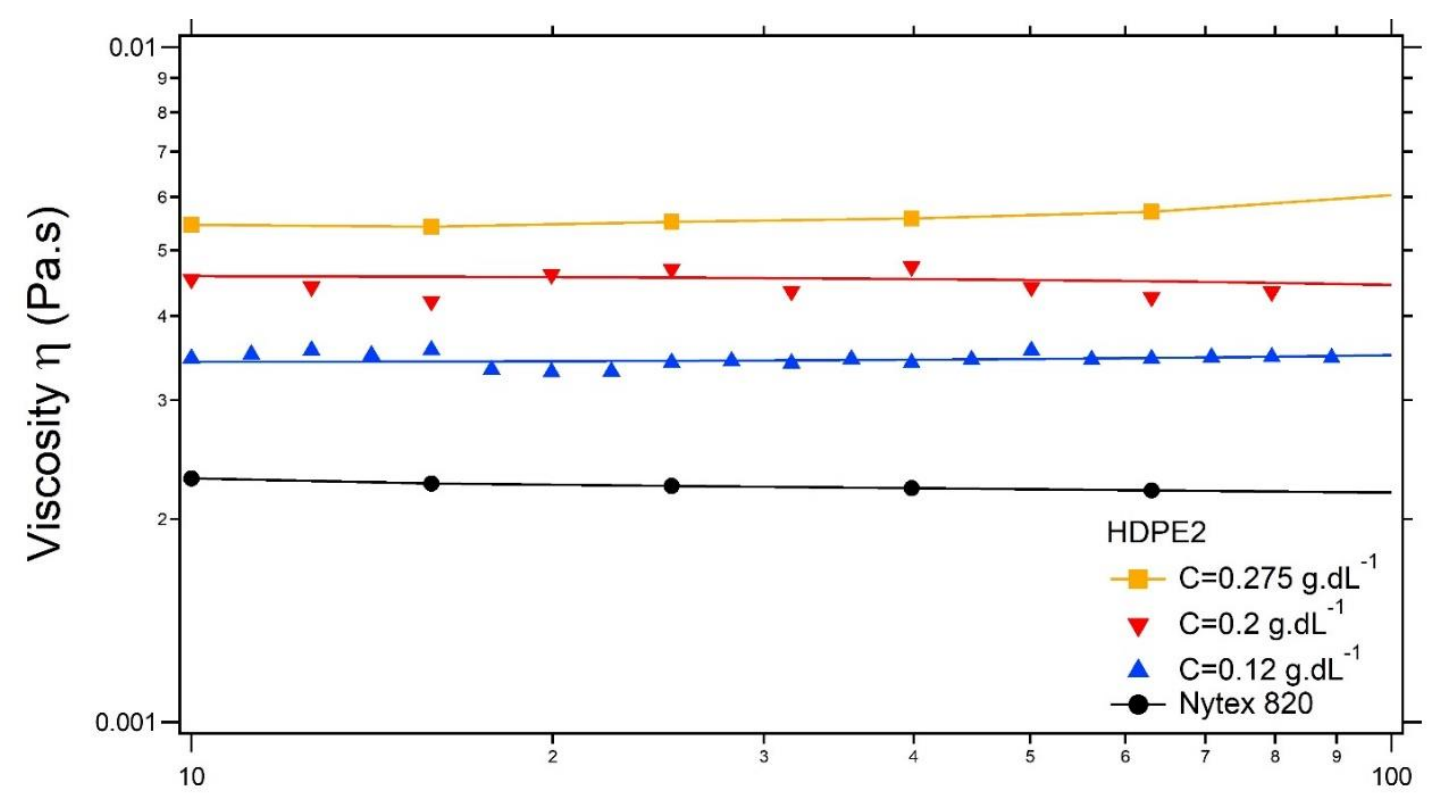

Shear rate $\dot{\gamma}(1 / s)$

Figure S5 : Viscosity as a function of shear rate of HDPE2 (441 $\left.\mathrm{kg} . \mathrm{mol}^{-1}\right)$ solutions in Nytex 820 oil at different concentrations $\left(T=165^{\circ} \mathrm{C}\right)$. 


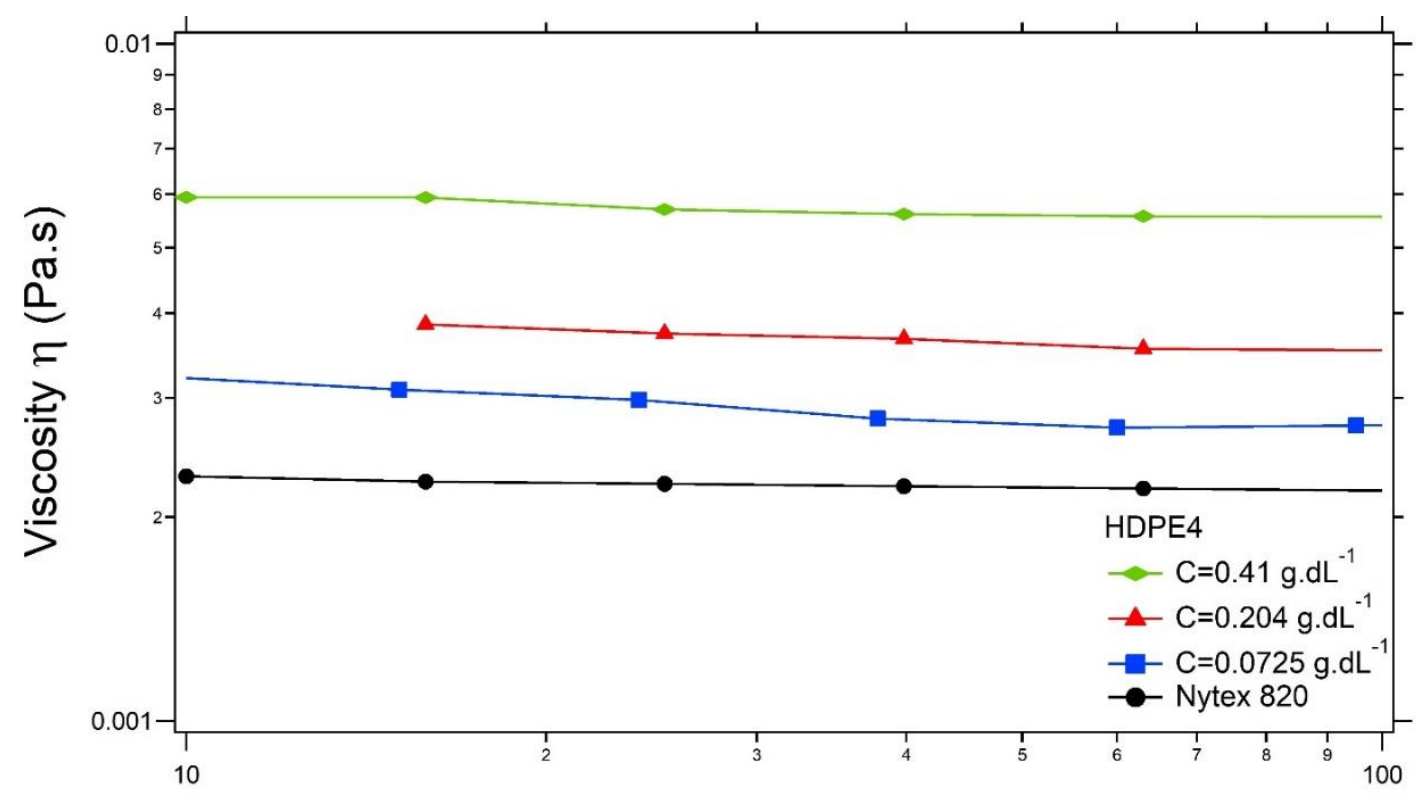

Shear rate $\dot{\gamma}\left(\mathrm{s}^{-1}\right)$

Figure S6 : Viscosity as a function of shear rate of HDPE4 $\left(278 \mathrm{~kg}^{\mathrm{mol}} \mathrm{m}^{-1}\right)$ solutions in Nytex 820 oil at different concentrations $\left(T=165^{\circ} \mathrm{C}\right)$.

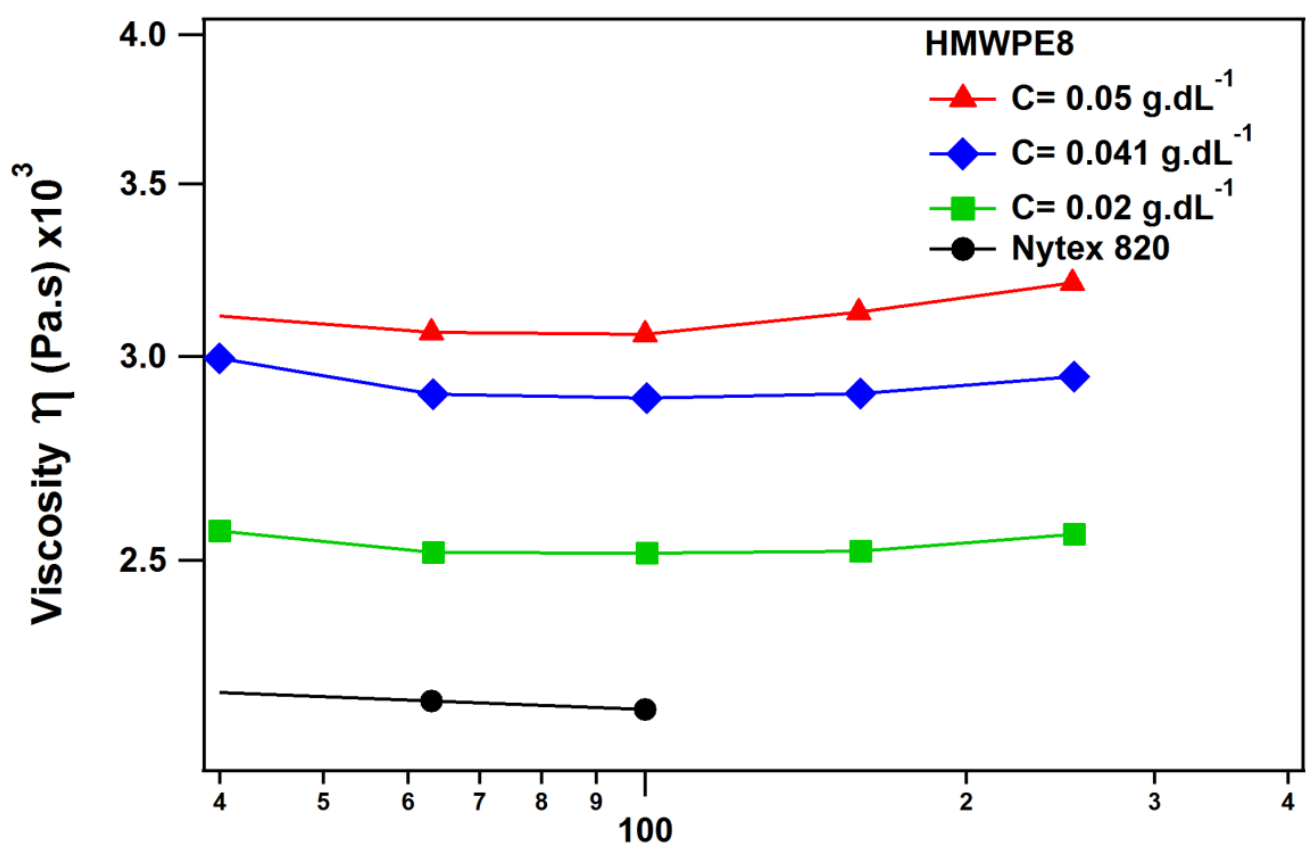

Shear rate $\dot{\gamma}(1 / s)$

Figure S7 : Viscosity as a function of shear rate of HMWPE8 $\left(1140 \mathrm{~kg} \cdot \mathrm{mol}^{-1}\right)$ solutions in Nytex 820 oil at different concentrations $\left(T=165^{\circ} \mathrm{C}\right)$. 
Determination of the intrinsic viscosity for all PE samples (Kraemer and Huggins plots) :

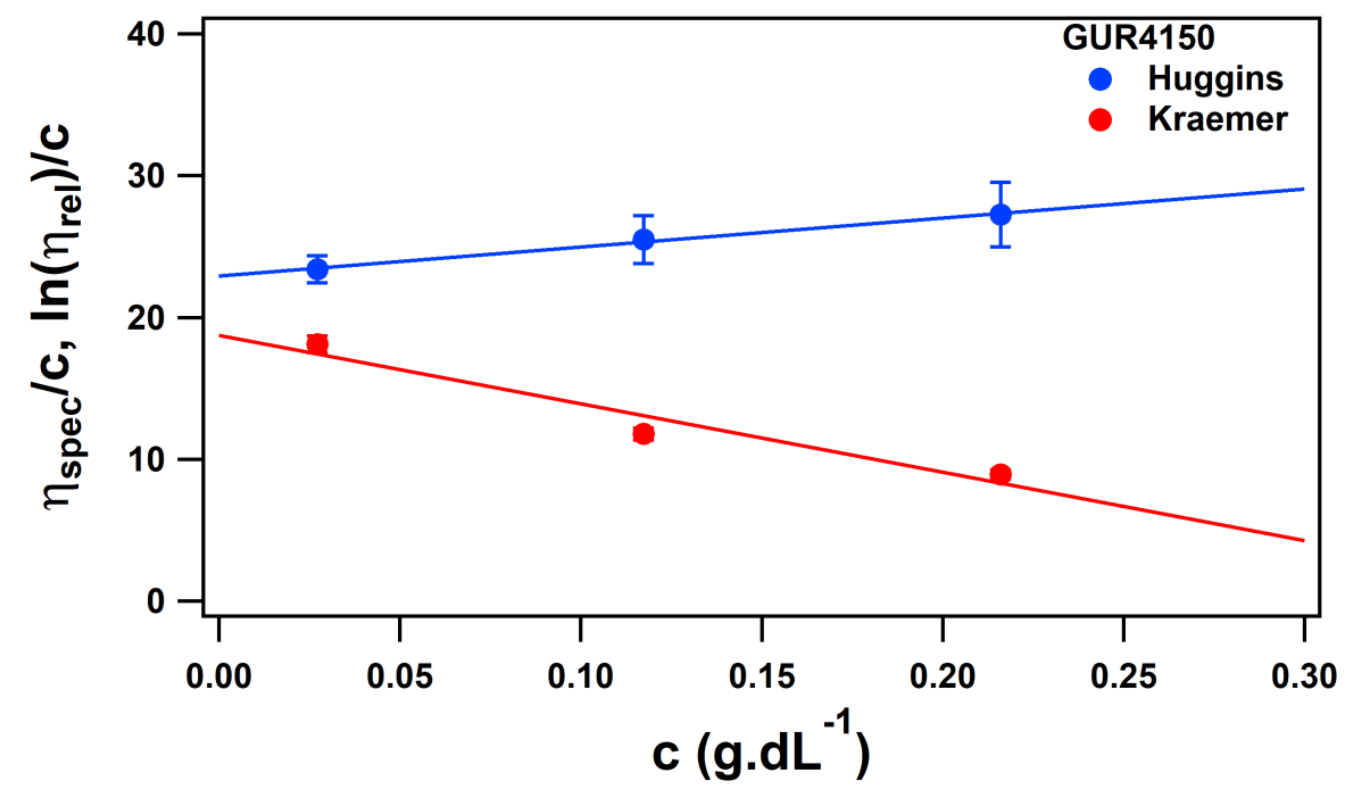

Figure S8 : Kraemer's inherent viscosity and Huggins' reduced viscosity as a function of the concentration for UHMWPE GUR4150.

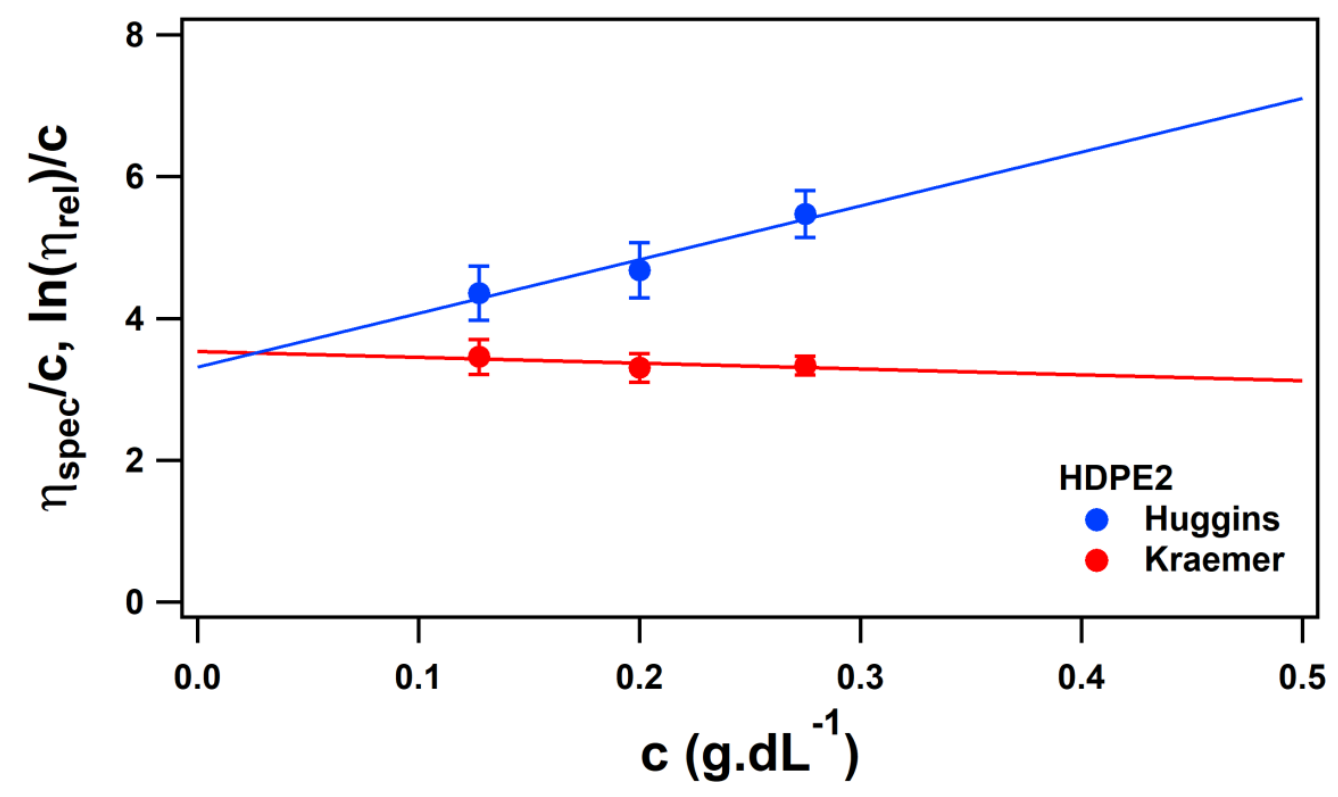

Figure S9 : Kraemer's inherent viscosity and Huggins' reduced viscosity as a function of the concentration for HDPE2 $\left(441 \mathrm{~kg}^{\mathrm{mol}} \mathrm{m}^{-1}\right)$ 


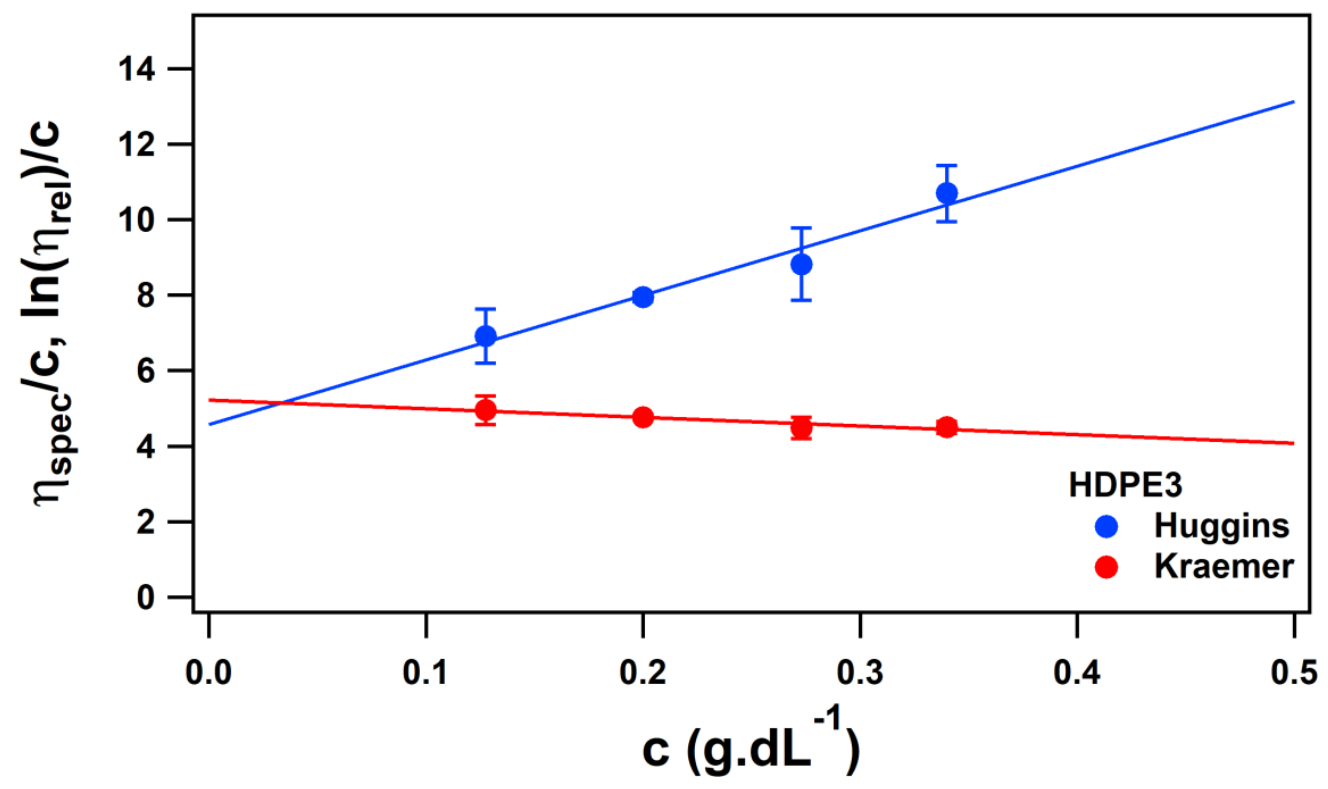

Figure S10 : Kraemer's inherent viscosity and Huggins' reduced viscosity as a function of the concentration for HDPE3 $\left(693 \mathrm{~kg}^{\mathrm{mol}} \mathrm{mo}^{-1}\right)$

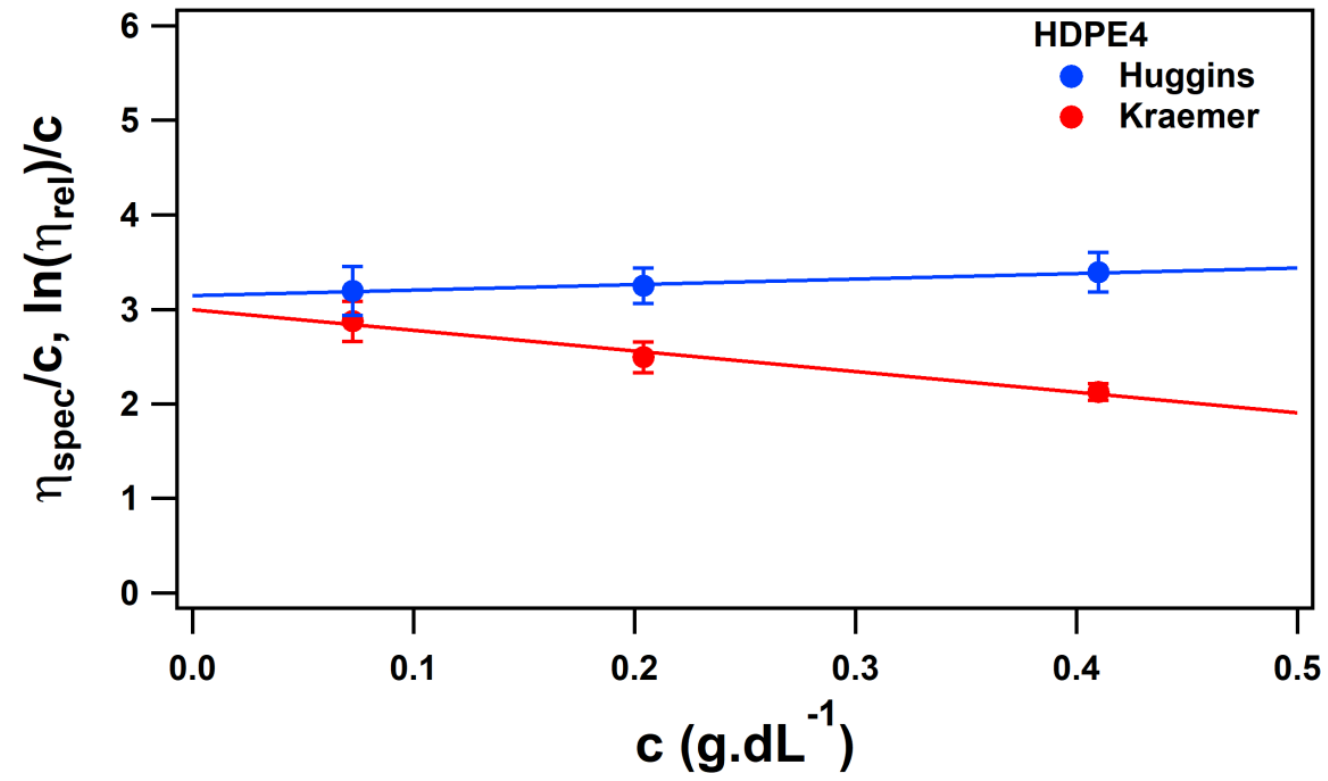

Figure S11 : Kraemer's inherent viscosity and Huggins' reduced viscosity as a function of the concentration for HDPE4 (278 kg. mol-1) 


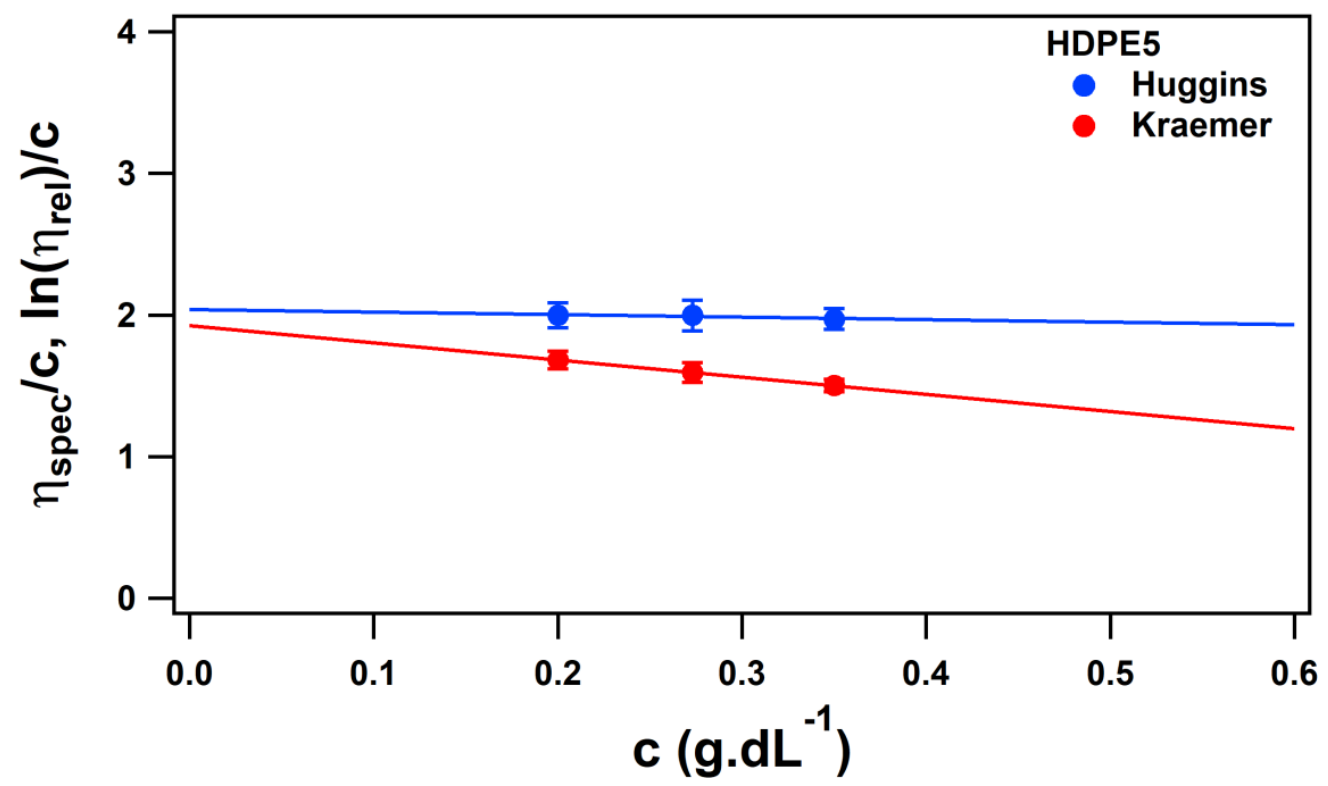

Figure S12 : Kraemer's inherent viscosity and Huggins' reduced viscosity as a function of the concentration for HDPE5 (145 kg.mol-1)

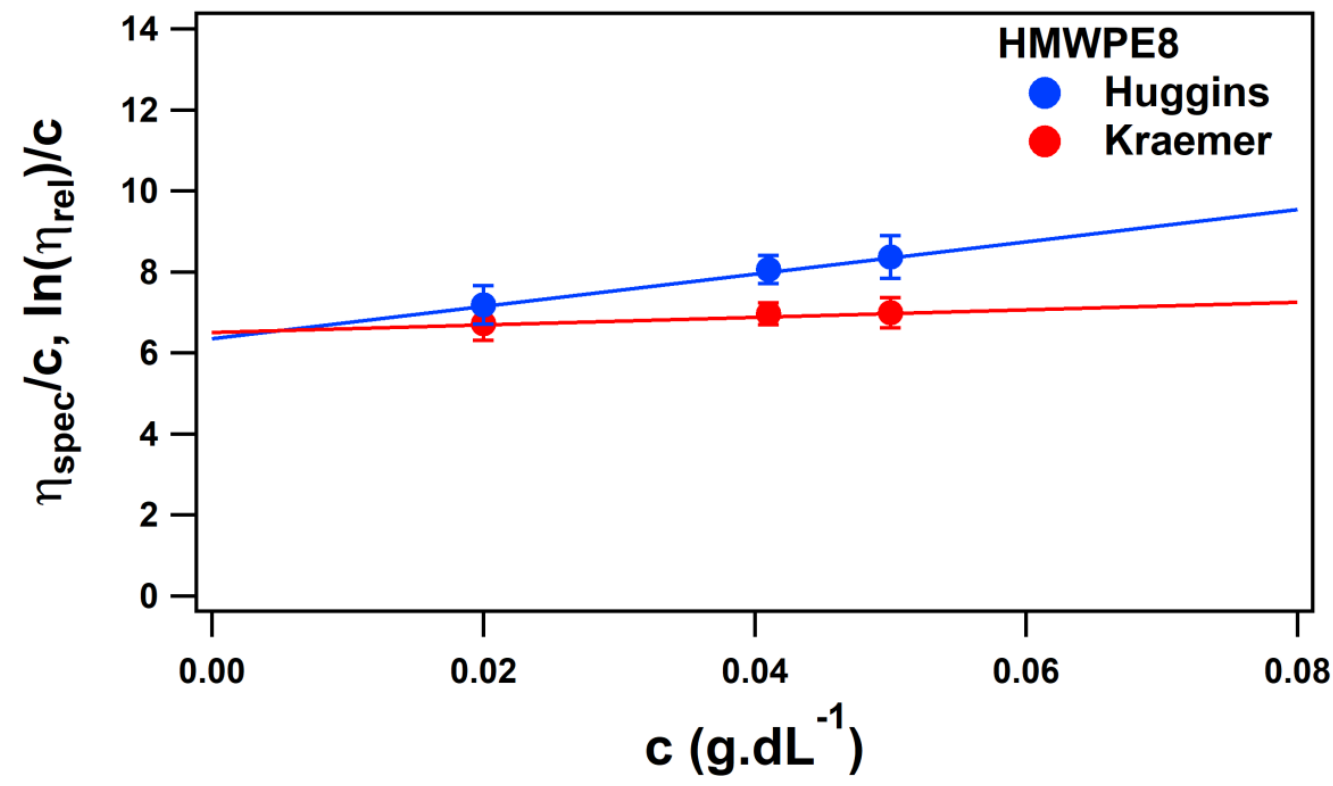

Figure S13 : Kraemer's inherent viscosity and Huggins' reduced viscosity as a function of the concentration for HMWPE8. 